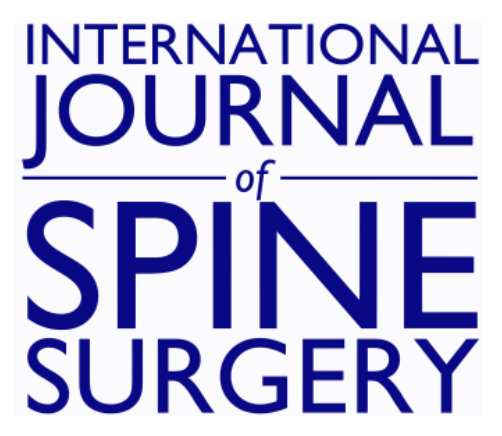

\title{
Clinical Outcomes of a Polyaxial Interspinous Fusion System
}

Joseph A. Sclafani, Kevin Liang, Donna D. Ohnmeiss and Charles Gordon

Int J Spine Surg 2014, 8 ()

doi: https://doi.org/10.14444/1035

http://ijssurgery.com/content/8/35

This information is current as of April 26, 2023.

Email Alerts Receive free email-alerts when new articles cite this article. Sign up at: http://ijssurgery.com/alerts

The International Journal of Spine Surgery

2397 Waterbury Circle, Suite 1,

Aurora, IL 60504, Phone: +1-630-375-1432 


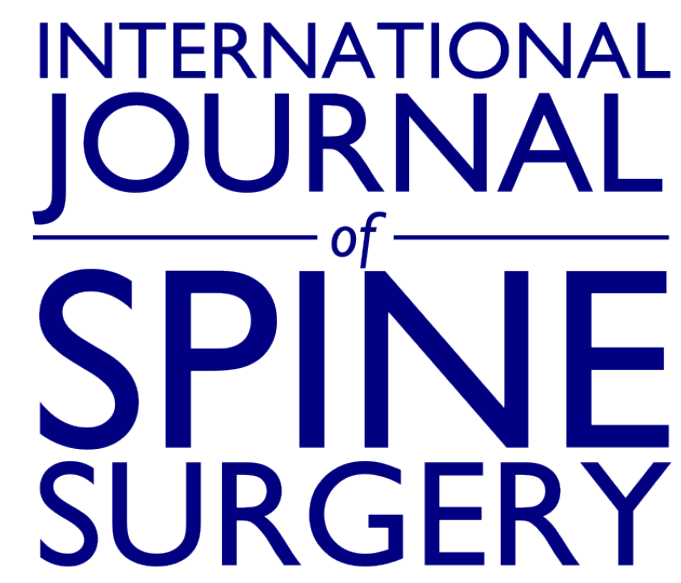

This article generously published free of charge by the International Society for the Advancement of Spine Surgery.

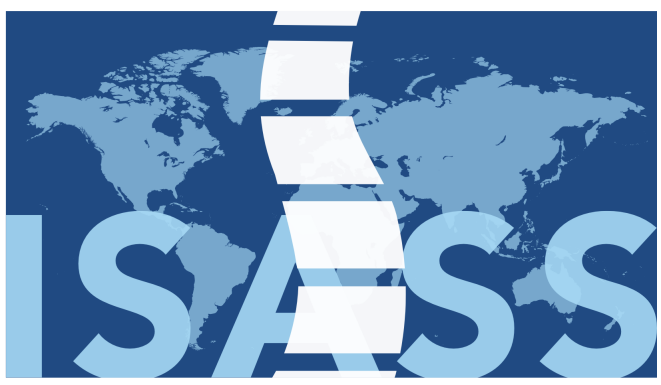

INTERNATIONAL SOCIETY for the ADVANCEMENT of SPINE SURGERY 


\section{Clinical Outcomes of a Polyaxial Interspinous Fusion System}

Joseph A. Sclafani MD, ${ }^{1}$ Kevin Liang Ph.D, ${ }^{1}$ Donna D. Ohnmeiss Dr. Med., ${ }^{2}$ Charles Gordon MD

${ }^{1}$ Milestone Research Organization, ${ }^{2}$ Texas Back Institute, ${ }^{3}$ Precision Spine Care

\section{Abstract}

\section{Background}

Early interspinous process fixation constructs utilize rigid fixation plates with immobile spikes which increase the difficulty of device implantation when anatomic variations are encountered. Second generation systems have been designed with polyaxial properties with the goal of accommodating natural osseous anatomic variations to achieve optimal implant placement and fixation integrity. The purpose of this study was to evaluate clinical outcomes in patients treated with this device to supplement the biomechanical data from previous studies.

\section{Methods}

A retrospective, non-randomized, single-center chart review at or beyond the one year postoperative time point was conducted to collect preoperative and perioperative data on patients treated with a polyaxial intraspinous fixation system. A postoperative numerical pain rating scale and modified $\mathrm{MacNab}$ classification score were obtained from each patient in the cohort via phone survey.

\section{Results}

A total of 53 patients were included in the study. Median hospital stay was 2 days (range 1-7 days). There were no reported perioperative blood transfusions or cases of radiographic fracture/migration of the device at the 6 week post-operative time point. There was a significant improvement in pain index score in the overall patient study group and a satisfactory (excellent or good) MacNab result was obtained in $48 \%$ of all patients. Patients with preoperative pain scores greater than $8 / 10$ reported more pain improvement than patients with preoperative pain scores less than 5 ( 0 points, $\mathrm{p}=0.96$, $\mathrm{n}=8$ ). Patients with a BMI less than 30 had significantly better MacNab outcome classifications than patients with a BMI greater than 30 .

\section{Conclusions}

The polyaxial interspinous fusion system produces significant clinical improvement when employed to treat patients with stenosis, herniated disc, or low grade spondylolisthesis. This device can be implanted with a low complication rate and short postoperative 
hospital admission time. Patients with high pre-operative pain score and BMI under 30 can be predictors of better clinical outcome and should be considered prior to implantation.

keywords: Interspinous process fusion, clinical outcome, minimally invasive spine surgery Volume 8 Article 35 doi: 10.14444/1035

\section{Introduction}

Spinal decompression and fusion techniques have been the standard of care for conditions of instability and deformity of the lumbar spine for the past 50 years. ${ }^{1,2,3}$ Several methods and techniques have been developed to accomplish suitable stabilization after segmental decompression. Traditional posterior spinal fusion constructs utilizing only transpedicular screws to achieve supplemental fixation allow for high postoperative fusion rates, but are associated with inherent risks to the patient and surgeon during implantation. These risks consist of nerve damage, damage to perineural structures, deep wound infection, as well as significant radiation exposure to the surgeon/patient/operating room staff during implantation. ${ }^{4}$

Initial development of interspinous devices was focused on creating a dynamic standalone treatment modality for neurogenic claudication that would not require concurrent open decompression surgery. There have been several design iterations of interspinous devices since the original Wallis system (Abbott Spine) and the X-Stop device (St. Francis/ Medtronic) were introduced in 1986 and 2005, respectively. ${ }^{5,6}$ These designs focused on two key biomechanical mechanisms. First, this type of device creates longitudinal distraction along the spinal column to increase the breadth of the neural foramina. Second, there is distraction of posterior elements and production of a focal area of relative kyphosis between two segments ${ }^{7}$. Cadaveric and in vivo studies demonstrate this segmental distraction reduces ligamentum flavum projection into the spinal canal. ${ }^{8,9,10}$ These occurrences increase the structural diameter of the neural foramina and decrease impingement of the exiting nerve root.

Although interspinous systems were initially designed to function as standalone devices for the treatment of stenosis through distraction/indirect decompression of the spinal canal, newer designs have recently been used in conjunction with anterior column reconstruction procedures as an alternate method of posterior spinal fixation. ${ }^{4,11,12}$ Use of interspinous fusion devices as supplemental fixation to achieve fusion for degenerative disc disease (DDD), spondylolisthesis, trauma, and tumor is designed to minimize the intraoperative risks associated with pedicle screw insertion. Many of these implants utilize rigid plates with fixed spikes to achieve fixation at the desired levels. ${ }^{4}$

The OsteoMed PrimaLOK SP Interspinous Fusion System is a novel, second generation fusion device which employs multiple polyaxial features to better accommodate natural osseous anatomic variations and achieve optimal implant fixation integrity (Figure 1). An early cadaveric biomechanical study of this interspinous fusion system used as 
supplemental fixation demonstrated significantly reduced flexion-extension, lateral bending, and axial rotation range of motion compared to native segments under physiologic loads. ${ }^{13}$

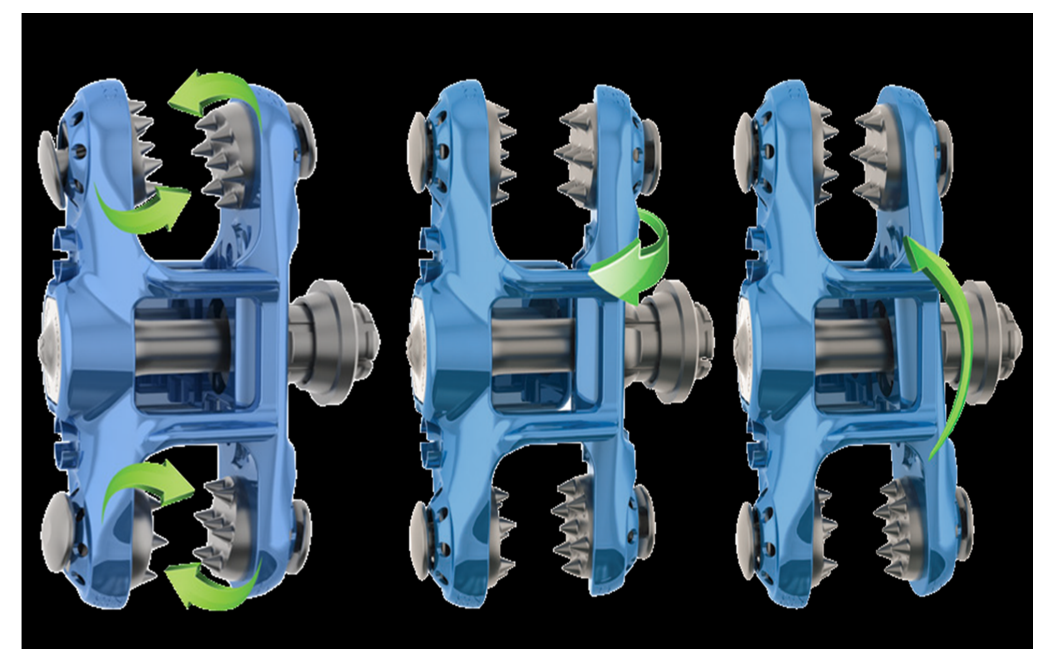

Fig. 1. An interspinous process fusion device demonstrating polyaxial properties.

For the lumbar spine, clinical instability can be characterized by excessive sagittal plane translation, and the high incidence of clinically evident disc disease at L4-L5 and L5-S1 can be attributed to these segments bearing the highest loads and experiencing the most motion in the sagittal plane. ${ }^{14}$ Therefore, reducing the range of motion is paramount in treating instability, and ultimately the goal of spinal fixation strategies is to achieve rigid stabilization to promote fusion. ${ }^{11,12,15}$ However, there have not previously been studies to determine the clinical outcome of patients treated with a polyaxial interspinous fusion system.

This retrospective study of patients treated with a second generation polyaxial interspinous fusion system has been designed to collect clinical outcome information to supplement the previous biomechanical study.

\section{Methods}

A retrospective, non-randomized, single-center chart review was conducted for all patients with a second generation polyaxial interspinous fusion implant who had reached the one year postoperative time point. Following Institutional Review Board approval, preoperative patient demographics (age, gender, BMI, diagnosis, previous spine surgery, pain severity score, Worker's Compensation claims) were collected through the chart review. Operative and perioperative data were obtained from available operative reports and hospital discharge summaries by an on-site research coordinator. postoperative complication rate was assessed from follow-up clinical documentation. Radiology reports interpreted by an unaffiliated residency-trained radiologist were used to assess the 6 week postoperative radiographic complication (fracture or implant migration) rate. A postoperative 1-10 pain score and modified Macnab classification score was obtained from each patient in the cohort via phone survey and retrospective analysis. All data were electronically collected and patient information was de-identified prior to analysis by an independent clinical research organization. 
Data were segmented based on age ( $<59$ years versus $\geq 59$ years), gender, primary indication, operative level, previous lumbar surgery, BMI, co-morbidity and preoperative pain score for outcome measure analysis. Statistical analyses of pain index scores were performed via either a one-way ANOVA or paired t-tests with significance defined as $\mathrm{p}<0.05$. Data are reported as means $\pm \mathrm{SD}$.

Statistical analysis of Macnab classification was performed using either Fisher's twotailed exact test or chi-squared method with Yate's correlation. A successful Macnab outcome is defined as an excellent or good classification. Significance is defined as $\mathrm{p}<0.05$.

\section{Results}

Fifty-three patients (29 female, 24 male) initially fulfilled the study criteria, and 3 patients were deceased (94\% follow-up rate, Table 1). No patients were treated under a Worker's Compensation claim. Subjects had a mean age of 60 years (range: $34-89$ years) at the time of surgery. The most common primary surgical indications were DDD with stenosis (45.3\%), herniated disc (HNP, 18.9\%) and spondylolisthesis (11.3\%).

\begin{tabular}{|l|l|}
\hline Table 1. Summary of patient demogr & n \\
\hline No. patients & 53 \\
\hline Age at surgery & 60 years \\
\hline Sex (Male:Female) & $24: 29$ \\
\hline Initial Diagnosis & \\
\hline Spinal Stenosis & 24 \\
\hline Herniated Disc & 10 \\
\hline Spondylolisthesis & 5 \\
\hline Follow-up period (average) & 22 months \\
\hline Follow-up rate & $94 \%(50 / 53)$ \\
\hline
\end{tabular}

A posterior-lateral approach to decompression was used in conjunction with posterior spinal instrumentation in all patients. Thirty four patients were implanted with the PrimaLOK SP device, sixteen patients received both a PEEK interbody cage and the PrimaLOK SP device, and three patients received pedicle screw instrumentation, a PEEK interbody cage and the PrimaLOK SP device. The average length of surgery was $105 \pm 43$ minutes. No patients required a perioperative blood transfusion. Complications included intraoperative dural tear $(\mathrm{n}=1)$ and readmission for intractable pain after a post-discharge mechanical fall $(n=1)$. There were no cases of fracture or migration of the device observed at the 6 week postoperative time point. However, there were 4 cases of hardware removal and 2 cases of re-operation for adjacent level disease during the follow up period. Median hospital admission time was 2 days (range 1-7 days) and half of all patients were discharged within one day of surgery. 
The pain index score improved from $7.17 \pm 1.68$ to $4.48 \pm 2.8$ ( $\mathrm{p}=0.0001,22$ months average follow up) for the overall study group (Table 2). There were 6 cases of excellent, 18 cases of good, 21 cases of fair and 5 cases of poor Macnab outcome among all subjects (Table 3). Improvement in pain index score was similar when stratified by age or gender $(\mathrm{p}>0.05)$. There was a significantly better Macnab outcome for the $\geq 59$ year old group (63\% satisfactory) than for the $<59$ year old group ( $26 \%$ satisfactory, Fisher's $\mathrm{p}=0.04$ ). Macnab outcome was similar between male and female groups (Fisher's $\mathrm{p}>0.05$ ).

Table 2. Pre- and postoperative pain scores collected through a retrospective chart review. Outcome scores were collected at a minimum 1 year postoperative time point. Note that there was a significant improvement in the overall pain score in all groups except for patients with a low $(<5 / 10)$ preoperative pain score. All surgical indications other than primary disc herniation had significant improvement in overall pain score after interspinous process fusion.

\begin{tabular}{|c|c|c|c|}
\hline & Preoperative Pain Score & Postoperative Pain Score & Paired t-test $p$ value \\
\hline Overall & $7.2 \pm 1.7$ & $4.5 \pm 2.8$ & $0.0001^{*}$ \\
\hline Male & $7.1 \pm 1.8$ & $4.2 \pm 2.9$ & $0.001 *$ \\
\hline Female & $7.2 \pm 1.6$ & $4.7 \pm 2.8$ & $0.001 *$ \\
\hline Age $>59$ & $7.3 \pm 1.9$ & $5.3 \pm 3.0$ & $0.05^{*}$ \\
\hline Age $\leq 59$ & $7.1 \pm 1.6$ & $3.9 \pm 2.6$ & $0.001^{*}$ \\
\hline Preoperative pain $\geq 8 / 10$ & $8.5 \pm 0.7$ & $5.0 \pm 3.1$ & $0.0001^{*}$ \\
\hline Preoperative pain $<5 / 10$ & $4.4 \pm 0.8$ & $4.4 \pm 2.5$ & $>0.05$ \\
\hline $\mathrm{BMI} \geq 30$ & $7.4 \pm 1.5$ & $5.4 \pm 2.8$ & $0.01 *$ \\
\hline $\mathrm{BMI}<30$ & $7.1 \pm 1.8$ & $4.0 \pm 2.7$ & $0.0001^{*}$ \\
\hline \multicolumn{4}{|l|}{ Diagnosis } \\
\hline Stenosis & $7.4 \pm 1.5$ & $4.5 \pm 2.8$ & $0.0001 *$ \\
\hline Herniated Disc & $7.0 \pm 2.0$ & $4.8 \pm 3.3$ & $>0.05$ \\
\hline Spondylolisthesis & $7.8 \pm 1.6$ & $3.2 \pm 3.1$ & $0.01 *$ \\
\hline \multicolumn{4}{|l|}{ Operative Level } \\
\hline $\mathrm{L} 2-3$ & $7.0 \pm 1.2$ & $5.8 \pm 1.1$ & $>0.05$ \\
\hline L3-4 & $7.4 \pm 2.1$ & $4.5 \pm 3.3$ & $>0.05$ \\
\hline L4-5 & $7.5 \pm 1.4$ & $4.3 \pm 2.4$ & $0.001^{*}$ \\
\hline L5-S1 & $5.9 \pm 1.7$ & $3.8 \pm 3.3$ & $>0.05$ \\
\hline
\end{tabular}

Table 3. Representation of successful Macnab outcome scores (excellent or good) by patient demographics, diagnosis and operative level. There was not a significant difference in success when stratified by gender, diagnosis or operative level. There was a significantly higher rate of surgical success in patients aged over 59 years compared to those less than 59 years old.

\begin{tabular}{|l|l|l|}
\hline & Excellent/Good & Fair/Poor \\
\hline Overall & $6 / 18(48 \%)$ & $21 / 5(52 \%)$ \\
\hline Male & $3 / 9(55 \%)$ & $8 / 2(43 \%)$ \\
\hline Female & $3 / 9(43 \%)$ & $13 / 3(57 \%)$ \\
\hline
\end{tabular}




\begin{tabular}{|l|l|l|}
\hline Age $>59$ & $5 / 12(59 \%)$ & $11 / 1(41 \%)$ \\
\hline Age $\leq 59$ & $1 / 6(33 \%)$ & $10 / 4(67 \%)$ \\
\hline Preoperative pain $\geq 8 / 10$ & $5 / 7(48 \%)$ & $10 / 3(52 \%)$ \\
\hline Preoperative pain $<5 / 10$ & $2 / 4(67 \%)$ & $3 / 0(33 \%)$ \\
\hline BMI $\geq 30$ & $2 / 2(24 \%)$ & $10 / 3(76 \%)$ \\
\hline BMI $<30$ & $4 / 16(61 \%)$ & $11 / 2(39 \%)$ \\
\hline Diagnosis: & $3 / 10(54 \%)$ & $9 / 2(46 \%)$ \\
\hline Stenosis & $2 / 2(80 \%)$ & $1 / 0(20 \%)$ \\
\hline Herniated Disc & $0 / 3(33 \%)$ & $6 / 0(67 \%)$ \\
\hline Spondylolisthesis & $2 / 4(55 \%)$ & $5 / 0(45 \%)$ \\
\hline Operative Level & & $3 / 1(5 \%)$ \\
\hline L2-3 & & \\
\hline L5-4 & & \\
\hline & & \\
\hline & & \\
\hline
\end{tabular}

There was significant postoperative improvement in pain index score for a primary surgical indication of DDD with lumbar stenosis $(2.75 \pm 2.63$ point improvement $(\mathrm{PI})$, $\mathrm{n}=25, \mathrm{p}=0.0001)$ and spondylolisthesis $(4.6 \pm 3.85 \mathrm{PI}, \mathrm{n}=6, \mathrm{p}=0.01)$. Pain index score improvement was not significant for the lumbar disc herniation ( $2.2 \pm 3.46 \mathrm{PI}, \mathrm{n}=10$, $\mathrm{p}>0.05)$ group. There was no difference in Macnab classification score between different primary surgical indication groups $\left(\chi^{2} \mathrm{p}>0.05\right)$. Significant pain index improvement was observed for subjects treated at L3-4 (2.82 $\pm 2.60 \mathrm{PI}, \mathrm{n}=11, \mathrm{p}=0.04)$ and L4-5 (3.35 \pm 2.83 PI, $\mathrm{n}=20, \mathrm{p}=0.0001)$ but not at L2-3 (1.2 $\pm 2.17 \mathrm{PI}, \mathrm{n}=5, \mathrm{p}=0.25)$ or L5-S1 (2.33 $\pm 3.28 \mathrm{PI}$, $\mathrm{n}=9, \mathrm{p}=0.1$ ). Macnab classification was similar between subjects treated at different operative levels $\left(\chi^{2} p>0.05\right)$. There was no significant difference in pain index or Macnab outcome between subjects treated with the second generation polyaxial interspinous fusion device, both a PEEK interbody cage and the second generation polyaxial interspinous fusion device, or pedicle screw instrumentation, a PEEK interbody cage and the second generation polyaxial interspinous fusion device.

Subjects who reported a preoperative pain level greater than $8 / 10$ had more pain index improvement ( $3.62 \pm 3.07 \mathrm{PI}, \mathrm{n}=26)$ than subjects with a preoperative pain score of less than $5 / 10(1.30 \pm 2.58 \mathrm{PI}, \mathrm{n}=10, \mathrm{p}=0.04)$ but there was no significant difference in Macnab classification outcome between the two groups (Fisher's $\mathrm{p}>0.05$ ).

Significant pain index improvement was observed for both the high BMI $(\geq 30)$ group $(1.53 \pm 3.2 \mathrm{PI}, \mathrm{n}=15, \mathrm{p}=0.01)$ and low BMI $(<30)$ group $(3.27 \pm 2.6 \mathrm{PI}, \mathrm{n}=30, \mathrm{p}=0.0001)$. The low BMI group had significantly better Macnab outcome scores $(60 \%$ satisfactory, $\mathrm{n}=30$ ) than the high BMI group ( $24 \%$ satisfactory, $\mathrm{n}=15$, Fisher's $\mathrm{p}=0.01$ ). There were no significant differences observed in pain index or Macnab classification outcomes when subjects were stratified based on tobacco use or previous lumbar surgical status. 


\section{Discussion}

The results of this study demonstrate that implantation of a second generation polyaxial interspinous fusion device for achieving supplemental fixation results in significant pain index score improvement and satisfactory postoperative Macnab classification regardless of patient age or gender. There was a low complication rate $(3.7 \%)$ and no cases that required a perioperative blood transfusion. Overall length of hospital stay compares favorably to previous studies of MIS and open posterior instrumentation after lumbar decompression. ${ }^{16}$

The ability of the posterior spinal elements to maintain structural integrity and accommodate stress forces exerted by an interspinous fixation system has been examined in previous studies. ${ }^{7}$ Sheperd et al measured the mechanical force required to fracture the spinous process of 32 specimens with average to below-average bone mineral density. ${ }^{17}$ They found a significant linear correlation between bone mineral density and bone strength. A mean load of $339 \mathrm{~N}$ was required to cause a spinous process failure with a $95 \%$ confidence interval of 257-447 Newtons. Talwar et al designed a study to test incidence of spinous process fracture during interspinous device implantation. ${ }^{18}$ This study showed a lateral load of 95-786 N was required to cause failure of the posterior spinal elements and there was no significant difference in load tolerance between the cranial, middle or caudal aspects of the spinous process. An insertional load of 10.5-150.2 Newtons was required for intraoperative device fixation. These results suggest intraoperative fracture of the most osteoporotic patients is a highly unlikely but feasible possibility. There were no cases of intraoperative or perioperative posterior element fracture or hardware migration in this retrospective study. These initial results advocate for sufficient structural integrity of the posterior spinal elements to accommodate an interspinous fusion device with polyaxial properties. However, previous analysis of complication rates of certain non-polyaxial interspinous designs has demonstrated a higher rate of early postoperative spinous process fracture. ${ }^{19}$

A high preoperative pain score, low body mass index, and advanced age at the time of surgery were all predictors of a better postoperative clinical outcome in this study. A significantly better Macnab classification was observed in higher aged and lower BMI patients and more improvement in pain index was noted in patients with high preoperative pain versus their respective comparison groups. Nevertheless, all groups benefited from significant pain index improvement postoperatively. The investigator's explanation for relative improved outcomes in the higher aged group can be attributed to lower overall physical demands and expectations postoperatively in this patient population. Body mass index has been shown to have no impact on health related quality of life outcome measures when pedicle screw instrumentation or rigid interspinous fixation systems are used as supplemental fixation to facilitate fusion. ${ }^{6,4,15}$ Additional investigation with administration of validated, health related quality of life measures to patients treated with polyaxial interspinous fixation would be useful to assess the relationship of BMI and outcome with this treatment modality. 
There was a 3.7\% incidence of adjacent level syndrome requiring re-operation over a 22 month average follow-up period in all patients treated with the second generation polyaxial interspinous fusion system. In other studies, the incidence of symptomatic adjacent segment disease ranges from 5.2 to 18.5 percent. ${ }^{22}$ The re-operation rate in this

study is consistent with the rate seen with other methods of posterior instrumentation. ${ }^{22,23}$

Lindsey et al studied the kinematic properties of a rigid interspinous fixation device implanted at the L3-4 level on multiple cadaveric models. ${ }^{24}$ They found no significant increase in motion at the adjacent L2-3 or L4-5 levels that would lead to adjacent level disease. Wiseman et al studied the effect of interspinous fusion device implantation at the L3-4 level on adjacent level facet forces in cadaver models. ${ }^{25}$ The adjacent level average pressure and force measurements at the L2-3 and L4-5 levels were similar in fused and native models. As a result, the authors concluded adjacent level facet pain or accelerated degeneration was unlikely to occur after interspinous fusion device implantation. Based on this evidence, a second generation polyaxial interspinous fusion device is unlikely to accelerate adjacent level disease after implantation.

A significant improvement in overall pain index score was observed for patients undergoing implantation of the second generation polyaxial interspinous fusion system in this study. A limitation of this study is that the participating site did not collect a preoperative assessment of low back and leg pain with the Visual Analog Scale or evaluate quality of life as part of its standard of care. Future prospective studies designed to collect pre- and postoperative VAS scores along with validated quality of life data are necessary to further distinguish if this postoperative improvement was predominantly in axial low back pain, radicular lower extremity pain or neurogenic claudication.

\section{References}

1. Herkowitz HN, Kurz LT. Degenerative lumbar spondylolisthesis with spinal stenosis. A prospective study comparing decompression with decompression and intertransverse process arthrodesis. J Bone Joint Surg Am 1991;73(6):802-8.

2. Hibbs RA. An operation for progressive spinal deformities. NY Med J 1911;93:1013.

3. Wiseman CM, Lindsey DP, Frederick AD, et al. The effect of an interspinous process implant on facet loading during extension.Spine. 2005;30:903-907.

4. Wang JC, Haid RW, Miller JS, Robinson JC. Comparison of CD HORIZON SPIRE spinous process plate stabilization and pedicle screw fixation after anterior lumbar interbody fusion. J Neurosurg Spine. 2006;4: 132-136.

5. Bowers C, Amini A, Dailey AT, Schmidt MH. Dynamic interspinous process stabilization: review of complications associated with the X-Stop device. Journal of Neurosurgery.2010; 28: E8.

6. Brussee P, Hauth J, Donk RD, Verbeek AL, Bartels RH. Self-rated evaluation of outcome of the implantation of interspinous process distraction (X-Stop) for neurogenic claudication. European Spine Journal. 2008; 17(2): 200-203.

7. Bono CM, Vaccaro AR, Interspinous process devices in the lumbar spine. J Spinal Disord Tech 2007;20:255-261.

8. Lee J, Hida K, Toshitaka S, et al. An interspinous process distractor (X STOP) for lumbar spinal stenosis in elderly patients. J Spinal Disord Tech. 2004;17:72-77. 
9. Richards JC, Majumdar S, Lindsey DP, et al. The treatment mechanism of an interspinous process implant for lumbar neurogenic intermittent claudication. Spine. 2005;30:744-749.

10. Siddiqui M, Nicol M, Karadimas E, et al. The positional magnetic resonance imaging changes in the lumbar spine following insertion of a novel interspinous process distraction device. Spine. 2005;30:2677-2682.

11. Karahalios DG, Kaibara E, Porter RW, et al. Biomechanics of a lumbar interspinous anchor with anterior lumbar interbody fusion. J Neurosurg Spine. 2010; 12: 372 380 .

12. Wang JC, Spenciner, D, Robinson JC. SPIRE spinous process stabilization plate: biomechanical evaluation of a novel technology. J Neurosurg Spine. 2006;4: 160-164.

13. Voronov LI, Tsitsopoulos PP,Havey RM, Potluri T, Zelenakova J, Carandang G,Kulkarni N, Schmierer D, Yap M, Patwardhan AG. Biomechanical assessment of a polyaxial interspinous plating system as an adjunct to interbody fusion. Poster Presentation Orthopedic Research Society Minneapolis, MN October 3-6, 2012. Oral Presentation ISASS Barcelona, Spain March 20-23, 2012.

14. White AA, Panjabi MM. Clinical Biomechanics of the Spine. 1990.

15. Zdeblick TA: A prospective, randomized study of lumbar fusion. Preliminary results. Spine18:983-991, 1993

16. Kepler CK, Yu AL, Gruskay JA, et al. Comparison of open and minimally invasive techniques for posterior lumbar instrumentation and fusion after open anterior lumbar interbody fusion. The Spine Journal. 2012.

17. Shepherd DET, Leahy JC, Mathias KJ, et al. Spinous process strength. Spine. 2000;25:319-323.

18. Talwar V, Lindsey DP, Frederick AD, et al. Insertion loads of the X STOP interspinous process distraction system designed to treat neurogenic intermittent claudication. Eur Spine J. 2005.

19. Kim DH, Tantorski M, Shaw J, et al. Occult spinous process fractures associated with interspinous process spacers. Spine (Phila Pa 1976) 2011;36(16):E1080-1085.

20. Djurasovic M, Bratcher KR, Glassman S D, Dimar JR, Carreon L Y. The effect of obesity on clinical outcomes after lumbar fusion. Spine. 2008; 33(16):1789-1792.

21. Rosen DS, Ferguson SD, Ogden AT, et al. Obesity and self-reported outcome after minimally invasive lumbar spinal fusion surgery. Neurosurgery. 2008;63. 956-960.

22. Park P, Garton HJ, Gala VC, et al. Adjacent segment disease after lumbar or lumbosacral fusion: review of the literature. Spine 2004;29:1938-44

23. Hilibrand A S, Robbins M. Adjacent segment degeneration and adjacent segment disease: the consequences of spinal fusion? The Spine Journal.2004; 4(6):S190-S194.

24. Lindsey DP, Swanson KE, Fuchs P, Hsu KY, Zucherman JF, Yerby SA: The effects of an interspinous implant on the kinematics of the instrumented and adjacent levels in the lumbar spine. Spine 2003; 28:2192-2197.

25. Wiseman CM, Lindsey DP, Frederick AD, et al. The effect of an interspinous process implant on facet loading during extension.Spine. 2005;30:903-907. 


\section{Disclosures}

Milestone Research Organization was hired as the clinical research organization to conduct the study. This entity was compensated to conduct the study, analyze results and author the manuscript. Charles Gordon, MD receives royalties from Osteomed.

Copyright (C) 2015 ISASS - International Society for the Advancement of Spine Surgery. To see more or order reprints or permissions, see http://ijssurgery.com. 